plans, mobilization systems, staffs organization, area management, casualty volume management, and training/exercise plans were examined.

Results: Responses were received from 146 hospitals (68.5\%). Most of respondent hospitals $(80 \%)$ had plans for mass casualty incidents, and $<10 \%$ had plans for specific events, e.g., chemical or biological weapon incidents. About $70 \%$ had a personnel response for public relationship and media, site security control, and medical inventories and supplies, but only $25 \%$ had considered cost-accounting, communication systems, a model for patient referals, and food and water supplies during disasters. Of the hospitals providing a disaster management plan for mobilization, only $44 \%$ described when, who, and how to activate the plan, $36 \%$ had the plan for team organization, and about $50 \%$ had area management according to triage of patients, casualty volume, disaster severity, etc. Of the hospitals in this study, $70 \%$ provided education for their staffs about incidents response, but only $40 \%$ had exercises or drills yearly. Conclusion: Hospitals generally are not well prepared in an organized fashion to treat victims of disaster in Taiwan, particularly for chemical or biological terrorism. The efforts to improve correspondence with international standards for disaster management will be required from local level to central government.

Keywords: disaster management; hospital disaster plan; mass casualty incident

Prebosp Disast Med 2002;17:s12-13.

\section{Preparedness for Mass Gatherings in the XVIII Winter Olympic Games in Nagano \\ Hirosbi Okudera}

Department of Emergency and Critical Care Medicine, Shinshu University School of Medicine; Medical Care Director, The Organizing Committee for the XVIII Olympic Winter Games, Nagano 1998 (NAOC), Japan

Objective: The focus of this paper was medical preparedness and its results during the XVIII Winter Olympic Games in Nagano.

Methods: Medical care at the Nagano Games was designed with special reference to the concept of mass gathering medicine. Medical clinics and First-Aid Stations were set up at a total of 37 locations. The Polyclinic was set up at the Olympic Village. First response teams were introduced at all venues. Ambulances and rescue teams were on stand-by at the Olympic Village, and all of the competition and non-competition venues. Two helicopters were available at the alpine skiing venues. Ten local hospitals were included in the Nagano Olympic Designated Hospital System. The NAOC established the Medical Command Center (MCC) for the purpose of supervising and directing medical care activities at all the venues.

Results: Among the 1,275,529 participants, there were 5,968 records of patient visits at the medical facilities provided by NAOC Medical Services (0.5\%). Ambulances were dispatched 63 times and helicopters five times for emergency transportation. The command system by MCC was effective in coordinating emergency transportation by ambulance and helicopter for the hospitalization of seriously injured/ill patients.

Conclusion: In management of large scale events, mass gathering medicine should be an important key concept. Keywords: clinics; coordination and control; first-aid stations; management; mass gathering; XVIII Winter Olympics

Prebosp Disast Med 2002;17:s13.

\section{Usage Review of Global Maritime Distress and Safety} System

Isao Nakajima; ${ }^{1}$ Yongguo Zhao,; Hiroshi Juzoji;, Hirotaka Kato; ${ }^{2}$ Sadaki Inokuchi; ${ }^{2}$ Atsushi Nakajima ${ }^{3}$

1. Tokai University Medical Research Institute, Japan

2. Tokai University Emergency Medical Center, Japan

3. National Aerospace Laboratory, Japan

Objectives: To clarify problems with the Emergency Position Indicating Radio Beacon (EPIRB), the ground terminal of the IMOs GMDSS (Global Maritime Distress and Safety System; COSPAS-SARSAT International Satellite System for Search and Rescue).

Investigations: Problems with EIPRBs have been known since 1986. The frequency of use of the EPIRBs has been very low, even since 1997 when the EPIRB became used by ocean racing yachts. An analysis of rescue records for ships requesting rescue in waters near Japan indicates that out of 7,771 people in distress, 1,450 were rescued by the Maritime Safety Agency, 4,062 were retrieved by other organizations, 2,089 helped themselves, and 170 were confirmed dead or missing. Only 119 people (14 cases) were saved using the COSPAS-SARSAT. Japan introduced COSPAS-SARSAT following suggestions made by IMO and deployed Local User Terminals (LUTs) to receive rescue signals on a 24-hour basis. However, this system has yet to prove its effectiveness in saving human lives.

Proposed New System: A victim-based, new, search and rescue system was proposed that includes use of the Geostationary Orbit Satellite (GEO) and a Global Positioning System (GPS). It will be tested in field experiments with NASDA's next generation mobile communications satellite (ETS-VIII) in 2003. This new system was described and its merits were discussed from the point of view of saving human lives.

Conclusion: The new search and rescue system discussed in the paper overcomes the limitation of EPIRBs, and has the potential to save more human lives.

Keywords: disaster medicine, maritime medicine, radio communication, satellite communication

Prebosp Disast Med 2002;17:s13.

\section{Damage}

Terrorist Bombing Disasters: Implications for

Emergency Department Response

Jeffrey Arnold, MD, FACEP, FAAEM

Department of Emergency Medicine, Baystate Medical Center, Tufts University School of Medicine, Springfield, Massachusetts USA 